\title{
Damage mechanism for high strength steel part frame without diaphragm
}

\author{
Y. Kimura \& T. Ishihara \\ Building Research Institute, Tohoku University, Japan
}

\begin{abstract}
Recently, the high tension steel with the yield stress of $800 \mathrm{kN} / \mathrm{mm}^{2}$ was developed, and the loading test of the structural members with this steel has been confirmed. It is shown that the ratio between ultimate strength and yield strength is almost unity, so that the members with this steel have quite small ductility. When rigid moment resisting frames with high tension steel are subjected to seismic force, the fracture at the ends of beam may occur and it causes the strength of frames to decrease. On the other hand, the semi-rigid moment resisting frames without diaphragm with high tension steel can absorb the seismic energy at the beam-to-column connections due to its plate bending deformation. This study performs cycle loading experiments to high tension steel part frames, and compares the initial rigidity and the yield strength of part frames without diaphragm with that of part frames with diaphragm. In addition, these experimental results are compared with the approximation of the reference.

Keywords: high strength steel, fracture, plate bending deformation, ultimate strength, diaphragmless.
\end{abstract}

\section{Introduction}

The new steel named H-SA700 has been developed to decrease the alloy element and to establish the streamlined process of heat treating in the project in Japan during 2004 and 2008. In the view of cost, it is better than the steel used with $800 \mathrm{~N} / \mathrm{mm}^{2}$. The main seismic frame with this new high strength steel has the possibility to keep elastic and the only damper becomes plastic, even though it is subjected to a large earthquake. On the other hand, it is shown that this new high strength steel has smaller fracture capacity and lower fatigue performance than the used steel of SS400 and SM490 with ultimate stress of $400 \mathrm{~N} / \mathrm{mm}^{2}-$ 
490N/mm ${ }^{2}$ (e.g. Shioaku et al. [1] and Tanaka et al. [2-4]), so that it needs to decrease the weld area to prevent fracture at the weld.

When the high strength steel is applied to the main moment resisting frame without diaphragm, the frame may keep elastic during large earthquake. In this paper, the cyclic tests for the part frame model with the difference of width and thickness of columns are performed to clarify the initial stiffness and yielding strength. When the column joint stiffness is high, the initial stiffness becomes high. The fracture near the weld area may occur as soon as the frame becomes plastic. On the other hand, when the column flexural stiffness is small, the initial stiffness and maximum strength become low and the fracture may not occur at the joint.

The joint without diaphragm is investigated to be able to be applied to the main steel frames with high strength steel. The approximations for the initial stiffness and yield strength, maximum strength are suggested to be applicable to the estimation of the experimental results.

\section{Cyclic loading test for part frame of beam and column}

\subsection{Guideline of cyclic loading test}

Figure 1 shows the set up for the part frames of beam and column. The boundary conditions of beam and column are pinned, and the cyclic horizontal load is applied by $500 \mathrm{kN}$ oil jack.

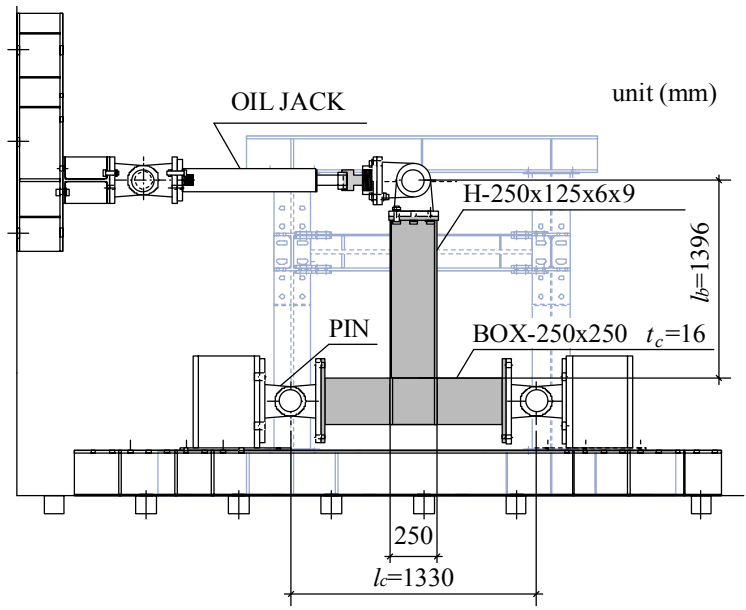

Figure 1: $\quad$ Test setup.

As shown in Table 1, there are 6 specimens of part frames with high strength steel. The specimen of No.1 has the diaphragm, and the others have no diaphragm. The specimens from No.2 to No.6 are different from the section of the column. The ratio of column moment capacity, $M_{p c}$, to beam moment capacity, $M_{p b}$ from No.2 to No.6 is the range from 1.8 to 4.4 . 
Table 1: $\quad$ Specimens.

\begin{tabular}{|c|c|c|c|}
\hline & Beam & Column & Diaphragm \\
\hline No.1 & $\mathrm{H}-250 \times 125 \times 6 \times 9$ & $\square-250 \times 16$ & Yes \\
\hline No. 2 & $\mathrm{H}-250 \times 125 \times 6 \times 9$ & $\square-250 \times 16$ & No \\
\hline No.3 & $\mathrm{H}-250 \times 125 \times 6 \times 9$ & $\square-200 \times 16$ & No \\
\hline No.4 & $\mathrm{H}-250 \times 125 \times 6 \times 9$ & $\square-300 \times 16$ & No \\
\hline No.5 & $\mathrm{H}-250 \times 125 \times 6 \times 9$ & $\square-250 \times 12$ & No \\
\hline No.6 & $\mathrm{H}-250 \times 125 \times 6 \times 9$ & $\square-250 \times 19$ & No \\
\hline
\end{tabular}

Figure 2 shows the cyclic loading procedure. In this procedure, the increment of the displacement at allowable bending moment of $\mathrm{H}$-shaped beam, $\delta_{F}$, is adopted, and after that, the increment of the displacement at yield bending moment capacity of H-shaped beam, $\delta_{y 0}$, is used.

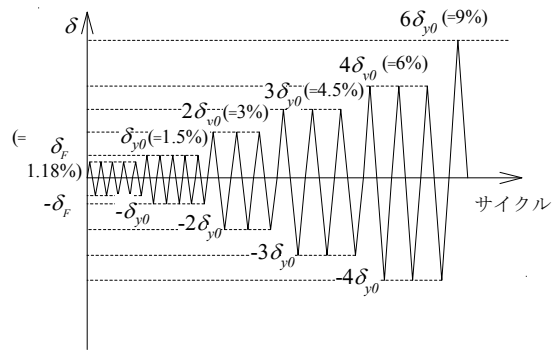

Figure 2: Cyclic loading procedure.

Figure 3 shows the specimen of No.2, and the strain gauges are also installed on the flange and web of $\mathrm{H}$-shaped beam and box column to investigate the local buckling of flange and web for $\mathrm{H}$-shaped beam and the local plate deformation of beam-to-column connections.

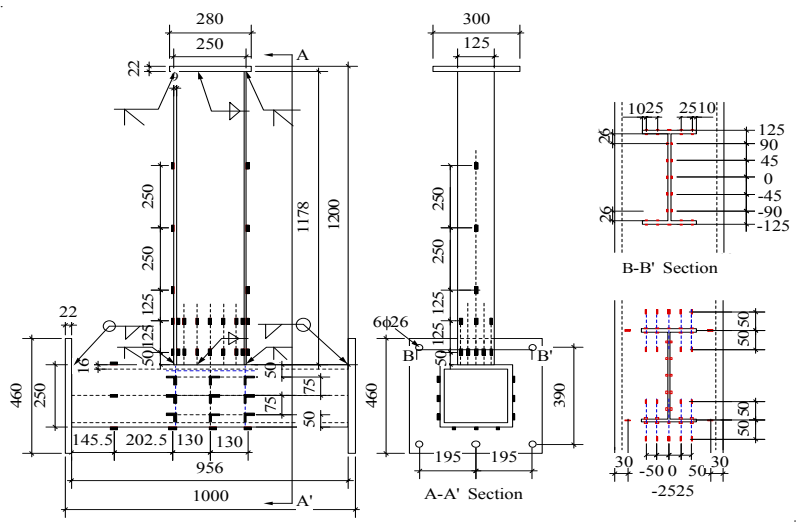

Figure 3: $\quad$ Specimen of No.2 with strain gages. 
Figure 4 shows the stress and strain curves for the high strength steel plates by tension test. The yield stress of each plate is about $735-810 \mathrm{~N} / \mathrm{mm}^{2}$, and the ultimate stress is about $810-860 \mathrm{~N} / \mathrm{mm}^{2}$.

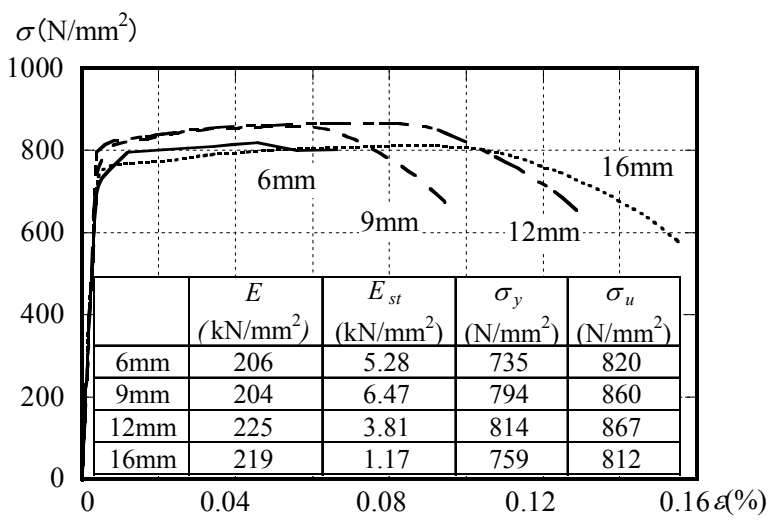

Figure 4: $\quad$ Material property of high strength steel plate.

\subsection{Results of cyclic loading test}

Figure 5 shows the hysteretic curves for specimens of No.1-No.6. $P_{y 0}$ and $\delta_{y 0}$ are the yield bending moment, $M_{y}$, divided by the length of the beam, and the horizontal displacement of the beam at the top. ${ }_{e} P_{F}$ or ${ }_{e} P_{y}$ means the load when the value at any strain gage reaches the strain corresponding to the allowable stress or the yield stress, respectively.

The approximation formula of the yield strength for part frame without diaphragm with SS400 or SM490 is suggested such as Equation (1) by (Akiyama et al. [6]).

$$
P_{y}=1.38_{c} \sigma_{y} t_{c}^{2}\left(2 \sqrt{\frac{B-t_{c}}{\left(B-t_{c}\right)-b}}+\frac{t_{r}}{\left(B-t_{c}\right)-b}\right)
$$

where $B$ or $b$ is the width of column or beam flange, and $t_{c}$ or $t_{r}$ is the column thickness or the weld thickness of the beam flange. ${ }_{c} \sigma_{y}$ is the yield stress of the column flange.

Black triangle in the diagram indicates the point of $1 / 2.5$ of the initial stiffness, which is recognized as the yield strength of the specimens defined by (Akiyama et al. [6]).

The maximum load for No.1 with diaphragm exceeds the yield strength of the beam, and the strength suddenly drops below 0.1 of the yield strength, $P_{y 0}$ at 2 of $\delta / \delta_{y 0}$. The cause of this strength deterioration is the fracture of the beam flange near the weld to the column flange. On the other hand, the maximum loads for No. $2 \sim$ No. 6 without diaphragm are lower than that for No.1, because of the local bending deformation of the column flange plate due to the bending moment of the beam. In all of specimens without diaphragm, No.3 with narrow column 


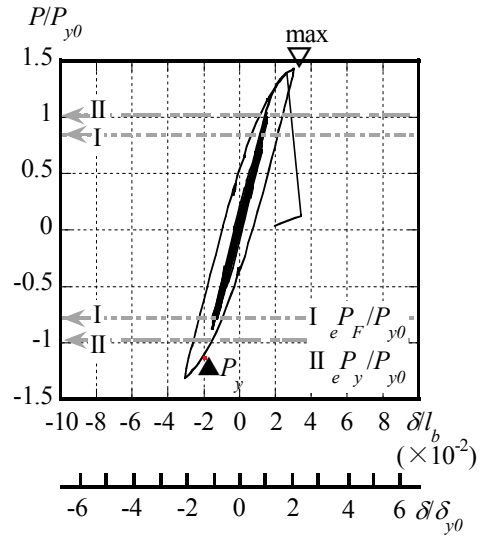

(a) No.1

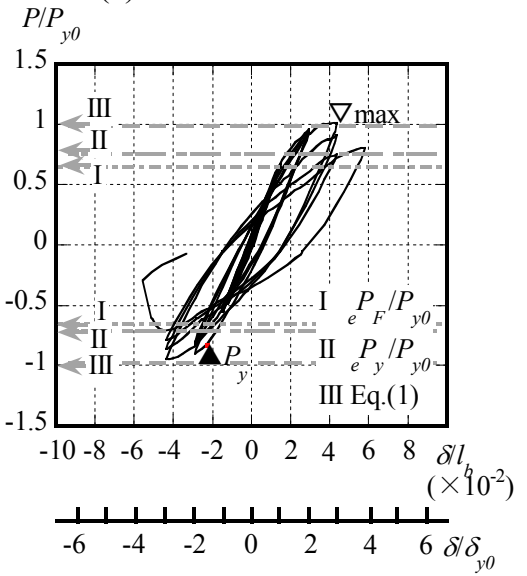

(c) No.3

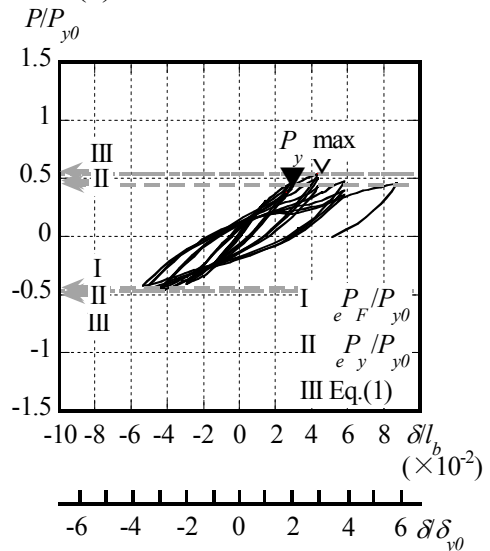

(e) No.5

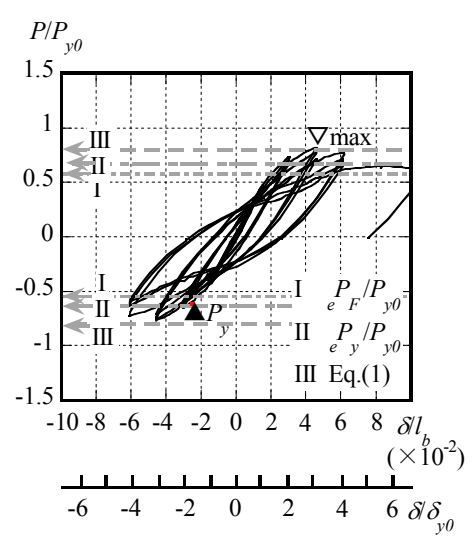

(b) No.2

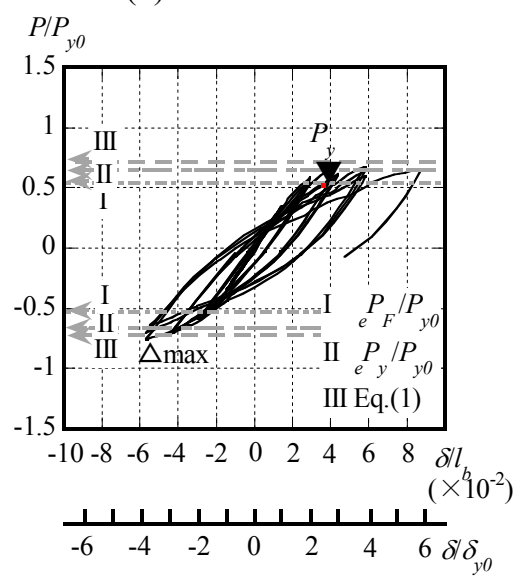

(d) No.4

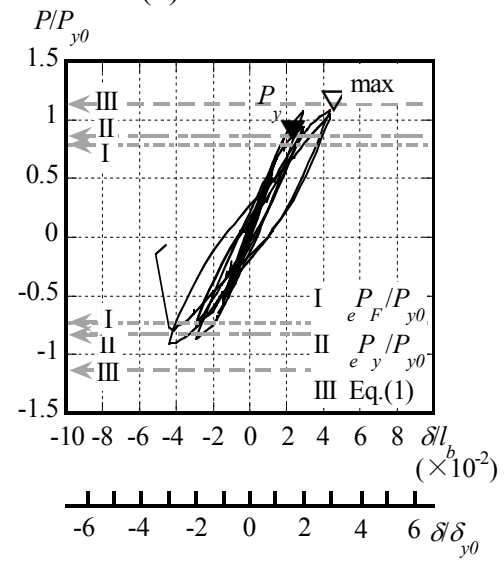

(f) No.6

Figure 5: Load-displacement curve for specimens. 
flange and No.6 with thick column flange has highest strength, and No.4 with wide column flange and No.5 with thin column flange has the highest ductility at the maximum load. The strength of all specimens without diaphragm decreases slowly.

Figure 6 shows the strain distribution on the column flange below beam flange such as the right diagram in Figure 3. For No.1 with diaphragm, the value of strain is almost equal to 0 , because the diaphragm carries the axial force of the beam flange to the column as the shear force (e.g. Suzuki et al. [5]). For No.2No.6 without diaphragm, the bending strain occurs on the column flange and strain values decrease near the column flange edge.

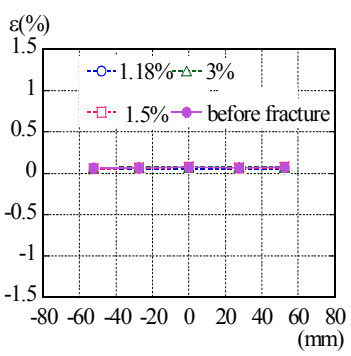

(a) No.1

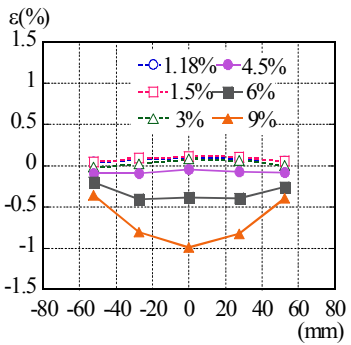

(d) No.4

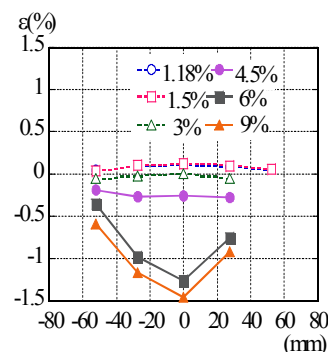

(b) No.2

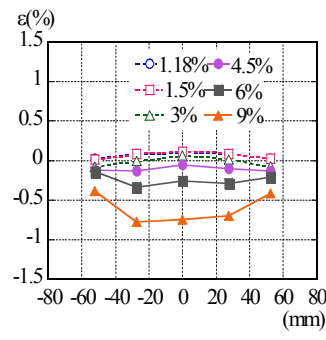

(e) No.5

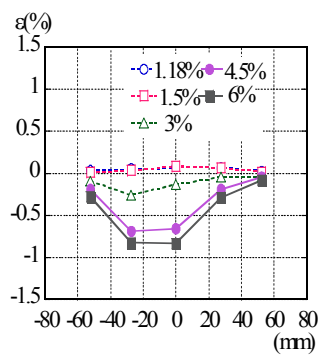

(c) No.3

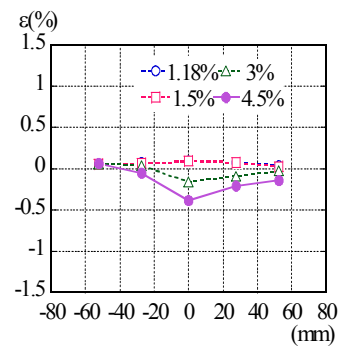

(f) No.6

Figure 6: Strain distribution on column flange below beam flange.

The strain value for No.3 and No.6 is smaller than the others, because the fracture by the tensile beam flanges early occurs. The strain value for No.2 is highest in all specimens, because the bending stiffness of the column flange for No.2 is higher than the others except the specimens with fracture and its beamto-column joint carries larger bending moment of the beam.

Figure 7 shows the collapse mechanism of the specimens. It is shown that for No.1, the fracture of the web of $\mathrm{H}$-shaped beam occurs as soon as the fracture of the tensile flange. On the other hand, for No.2, No.4 and No.5, the column flanges are shown to be drawn by the tensile beam flanges, and for No.3 and No.6, in addition to drawing of beam tensile flanges, the fracture near the weld of the flange and web occurs due to a higher rotational stiffness at the connection between the beam and the column than those of No.2, No.4 and No.5. 


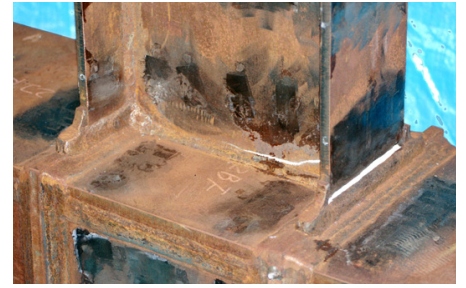

(a) No.1

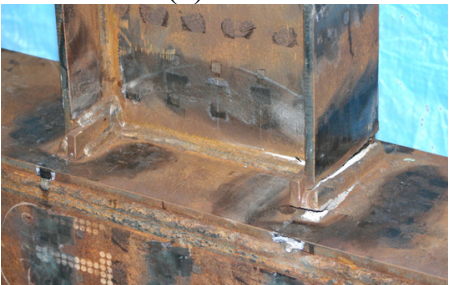

(c) No.3

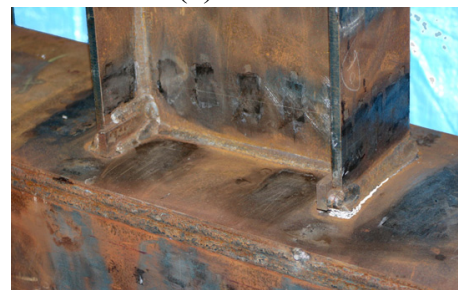

(e) No.5

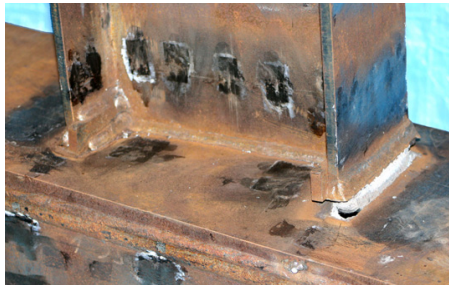

(b) No.2

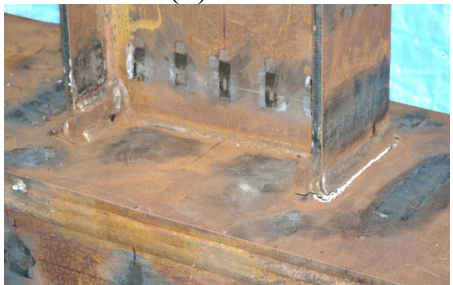

(d) No.4

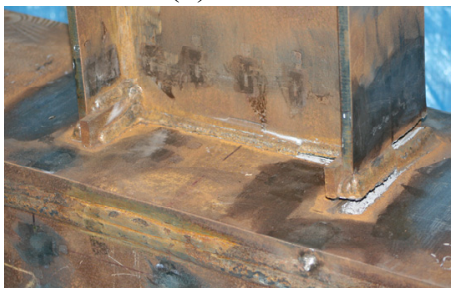

(f) No.6

Figure 7: Collapse mechanism of specimens.

\subsection{Estimation of part frame with high strength steel without diaphragm}

Figure 8 compare the initial stiffness between the experimental results and Equation (2) suggested by (Akiyama et al. [6]). Equation (2) is shown in the following.

$$
K_{y}=73 E I\left(\frac{b}{B-t_{c}}\right)^{3.5}\left(\frac{d-t_{f}}{b}\right)^{1.7}\left(\frac{B-t_{c}}{t_{c}}\right)^{0.5}
$$

where $E$ is the Young's modulus, $I$ is $t_{c}^{3} / 12 . d$ is the depth of the beam web and is the thickness of the beam flange.

$K_{y} / K_{y 0}$ of the vertical axis is the elastic stiffness of H-shaped beam as the cantilever. If $K_{y} / K_{y 0}$ is equal to 1 , it means that the beam-to-column joint becomes rigid. The values of the experimental results are distributed in $0.3-0.7$, so that all specimens without diaphragm are recognized as semi-rigid. Equation (2) can be applied in less than about 0.7 of $K_{y} / K_{y 0}$, so that the initial stiffness calculated by Equation (2) is almost same as the experimental results except No.6. 


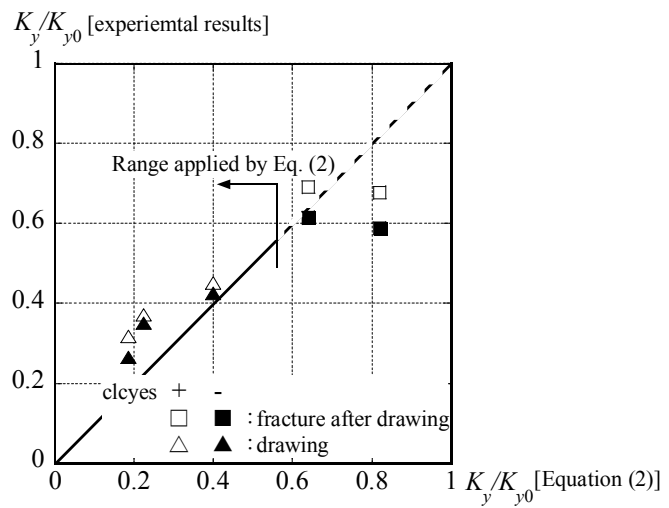

Figure 8: Comparison initial stiffness between experimental results and Equation (2).

Figure 9(a) compares the yield strength between the experimental results and Equation (1) suggested by (Akiyama et al. [6]), and Equation (3) is the approximation based on Equation (1) from the experimental results as the following.

$$
P_{y}=1.15_{c} \sigma_{y} t_{c}^{2}\left(2 \sqrt{\frac{B-t_{c}}{\left(B-t_{c}\right)-b}}+\frac{t_{r}}{\left(B-t_{c}\right)-b}\right)
$$

$P_{y 0}$ is the yield strength of H-shaped beam as the cantilever. Regardless of the collapse mechanism, the solid line by Equation (1) is higher than the experimental results, and the broken line by Equation (3) is almost same as the results. Because the yielding strength is calculated by general yield method of SS400 or SM490 and the stiffness of high strength steel after yielding is lower than SS400 or SM490.

Figure 9(b) compares the strength at first yielding between the experimental results and Equation (1) suggested by (Akiyama et al. [6]), and Equation (4) is the approximation based on Equation (1) from the experimental results as the following.

$$
{ }_{e} P_{y}=1.035_{c} \sigma_{y} t_{c}{ }^{2}\left(2 \sqrt{\frac{B-t_{c}}{\left(B-t_{c}\right)-b}}+\frac{t_{r}}{\left(B-t_{c}\right)-b}\right)
$$

$P_{F}$ or ${ }_{e} P_{y}$ means the load when the value at any strain gage reaches the strain corresponding to the allowable stress or the yield stress, respectively as shown in Figure 5. The solid line drawn by Equation (1) is higher than the experimental results, and the broken line drawn by Equation (4) corresponds to the lower bound. 


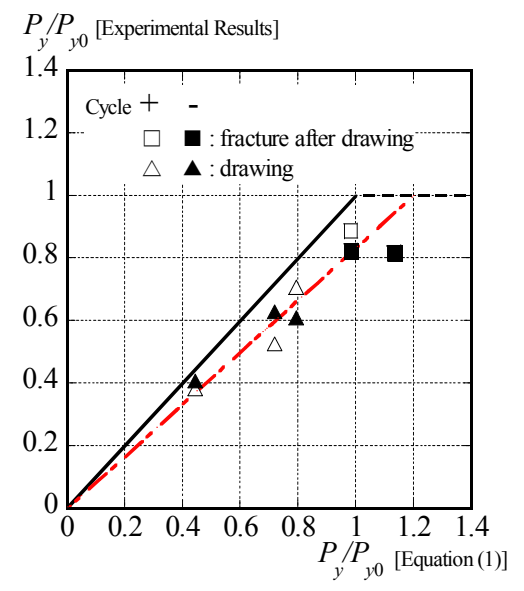

(a) yield strength

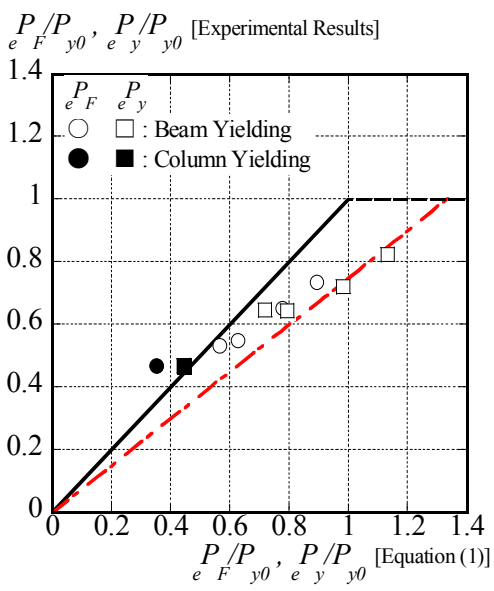

(b) local yield strength

Figure 9: Comparison of strength between experimental results and Equations (1) and (3).

\section{Conclusions}

1) For the part frame model with high strength steel without diaphragm, the initial stiffness and yield strength are lower than those for the part frame model with diaphragm. The initial stiffness and the yield strength without diaphragm are $40 \%-60 \%$ of those with diaphragm, respectively.

2) There are two kinds of collapse mechanism for the model without diaphragm. One of them is the drawing of column flange by beam flange for the wide column flange or thin column flange, and the other is the fracture after the drawing for the narrow column flange or thick column flange.

3) The model with diaphragm reaches the maximum strength due to fracture, and the strength decreases rapidly. On the other hand, the model without diaphragm increases its strength after drawing of column flange by beam flange, and has the high plastic deformation capacity.

4) The initial stiffness for the frame model without diaphragm is estimated with Equation (1), the yield strength for high strength steel is estimated with Equation (3) based on Equation (2) for the normal steel such as SS400 or SM490, because the stiffness of high strength steel after yielding is lower than SS400 or SM490.

\section{Acknowledgement}

This work was carried out under the general technology development project, "Development of Performance Assessment Methods for Innovative Structures Applying Advanced Structural Materials" by the Ministry of Land, Infrastructure, Transport and Tourism, Japan. 


\section{Reference}

[1] Shioaku, T. Yoshida, Y. Sakiyama, T. and Fukuda, T., Mechanical Properties of $800 \mathrm{~N} / \mathrm{mm}^{2}$ Class High Strength Steel, Summaries of Technical Papers of Annual Meeting, AIJ, C-2, pp. 613-614, 2008.

[2] Tanaka, N. Kaneko, T. Takenaka, H. and Sasaki, S., Elasto-Plastic Behavior of Circular-Column-to-H-shaped-Beam Connections Employing Super High Strength Steel: Part $1 \sim$ Part 3, Summaries of Technical Papers of Annual Meeting, AIJ, C-2, pp. 755-760, 2007.

[3] Tanaka, N. Kaneko, T. Suzui, Y. T. Takenaka, H. and Sasaki, S., ElastoPlastic Behavior of Circular-Column-to-H-shaped-Beam Connections Employing Super High Strength Steel: Part $4 \sim$ Part 6, Summaries of Technical Papers of Annual Meeting, AIJ, C-2, pp. 1009-1014, 2008.

[4] Tanaka, N. Suzuki, Y. T. Takenaka, H. and Sasaki, S., Elasto-Plastic Behavior of Circular-Column-to-H-shaped-Beam Connections Employing Super High Strength Steel: Part $7 \sim$ Part 9, Summaries of Technical Papers of Annual Meeting, AIJ, C-2, pp. 729-734, 2009.

[5] Suzuki, T. Ikarashi, K. Azuma, T. and Yoshinari, Y., A Study on Collapse Mode and Plastic Deformation Capacity of High Strength Steel Beam Connected to Box Column, Journal of Structural Construction Engineering, AIJ, 517, pp. 133-140, 1993.

[6] Akiyama, H. Oh, S. Otake, F. Fukuda, K. and Yamada S., General Moment-Rotation Characteristics of Beam-to-RHS Column Connections without Diaphragms, Journal of Structural Construction Engineering, AIJ, 484, pp. 131-140, 1996. 